\title{
Effect of preoperative inhaled budesonide on pulmonary injury after cardiopulmonary bypass: A randomized pilot study
}

\author{
Wei Gao, MD, Na Li, MS, Zhe-hao Jin, MS, Xiang-qi Lv, MD, and Xiao-guang Cui, MD
}

\section{ABSTRACT}

Background: Cardiopulmonary bypass can result in lung injury. This prospective, double-blinded, randomized trial aimed to evaluate the protective effect of inhaled budesonide on lung injury after cardiopulmonary bypass.

Methods: Sixty patients, aged 25 to 65 years, requiring cardiopulmonary bypass were randomized to groups treated with saline or budesonide inhalation preoperatively. The respiratory mechanics were recorded. Bronchoalveolar lavage fluid was collected before cardiopulmonary bypass and after sternal closure. Serum and bronchoalveolar lavage fluid levels of proinflammatory and anti-inflammatory factors were analyzed. The primary end point was the lowest ratio of the partial pressure of arterial oxygen to the fraction of inspired oxygen after cardiopulmonary bypass. The durations of ventilation and postoperative recovery time were noted.

Results: Budesonide significantly improved respiratory mechanics after cardiopulmonary bypass. Budesonide improved the partial pressure of arterial oxygen to the fraction of inspired oxygen ratio from 8 to 48 hours after the operation. Budesonide shortened the durations of mechanical ventilation and postoperative recovery time. Budesonide decreased the levels of proinflammatory factors while increasing the levels of anti-inflammatory factors in bronchoalveolar lavage fluid and serum (all $P<.05$ ). The macrophage and neutrophil counts, and protein and elastase concentrations were decreased by budesonide treatment.

Conclusions: Budesonide treatment shortened the durations of mechanical ventilation, inhibited local and systemic inflammation, and improved respiratory function after cardiopulmonary bypass. (J Thorac Cardiovasc Surg 2019;157:272-84)

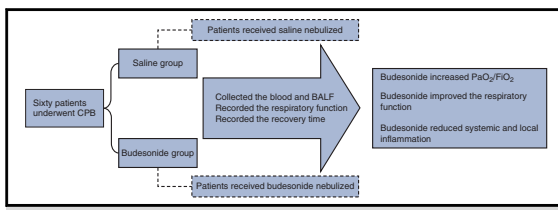

Preoperative budesonide improved the $\mathrm{PaO}_{2} / \mathrm{FiO}_{2}$ after CPB.

\section{Central Message}

Budesonide treatment reduced inflammation, improved respiratory function, shortened time of ventilation in the ICU, and promoted recovery after $\mathrm{CPB}$.

\section{Perspective}

$\overline{\mathrm{CPB}}$ can result in lung injury. Inflammation plays a key role in lung injury after $\mathrm{CPB}$ Preoperative budesonide treatment reduced lung injury and improved pulmonary function and recovery after $\mathrm{CPB}$. The protective effect of budesonide was mainly related to its anti-inflammatory function.

See Editorial Commentary page 285.

See Editorial page 270.
Postoperative pulmonary dysfunction is a frequent observation after cardiopulmonary bypass (CPB). ${ }^{1}$ Introduction of $\mathrm{CPB}$ circuits to the blood elements and lung ischemia/reperfusion injury inevitably activates the complement system, neutrophils, and macrophages, and then results in severe systemic

From the Department of Anesthesiology, the Second Affiliated Hospital of the Harbin Medical University, Harbin 150081, Heilongiiang Province, China.

This project was supported by a grant from the China Postdoctoral Science Funding (Grant No. 2015M581473). Chinese Clinical Trial Registry: ChiCTRIPC-15006179, March 31, 2015. Date and number of Institutional Review Board approval: April 28, 2014.

Received for publication March 8, 2018; revisions received Aug 23, 2018; accepted for publication Sept 4, 2018; available ahead of print Nov 2, 2018

Address for reprints: Xiao-guang Cui, MD, Department of Anesthesiology, the Second Affiliated Hospital of the Harbin Medical University, 246 Xuefu Rd, Harbin 150081, Heilongjiang Province, China (E-mail: cuixiaoguang66@163. com).

$0022-5223 / \$ 36.00$

Copyright (C) 2018 by The American Association for Thoracic Surgery

https://doi.org/10.1016/j.jtcvs.2018.09.017 and alveolar inflammation, especially lung inflammation. ${ }^{2-4}$ Postoperative pulmonary dysfunction can lead to severe clinical syndromes, including hypoxemia, pulmonary edema, and decreased lung compliance, and prolong the duration of mechanical ventilation as well as the lengths of stay in the intensive care unit (ICU) and the hospital, subsequently increasing mortality.

Several strategies have been investigated in attempts to ameliorate lung injury after $\mathrm{CPB}$, including antiinflammatory, antioxidative stress agents and improvement of pulmonary perfusion. ${ }^{6,7}$ Unfortunately, effective and

- Scanning this QR code will take you to the article title page to access supplementary information. 


\section{Abbreviations and Acronyms \\ ARDS = acute respiratory distress syndrome \\ BALF = bronchoalveolar lavage fluid \\ $\mathrm{CPB}=$ cardiopulmonary bypass \\ $\mathrm{CRP}=\mathrm{C}$-reactive protein \\ ICU = intensive care unit \\ IL = interleukin \\ $\mathrm{PaCO}_{2}=$ partial arterial carbon dioxide tension \\ $\mathrm{PaO}_{2} / \mathrm{FIO}_{2}=$ partial pressure of arterial oxygen to the fraction of inspired oxygen \\ $\mathrm{TNF}=$ tumor necrosis factor}

ideal management strategies are still under debate. ${ }^{1,8}$ Although corticosteroids can decrease proinflammatory factors, ${ }^{9,10}$ systemic corticosteroid administration induces immunosuppression and hyperglycemia, and the therapeutic effect is still a subject of debate. ${ }^{11,12}$ In contrast, inhaled budesonide has been found to reduce acute lung injury in experimental studies ${ }^{13-15}$ and to improve ventilatory mechanics and reduce the inflammatory response to 1-lung ventilation in clinical research. ${ }^{16}$

In the present study, we hypothesized that inhaled budesonide can ameliorate the lung injury induced by $\mathrm{CPB}$. The hypothesis was investigated by measuring the ratio of the partial pressure of arterial oxygen and the fraction of inspired oxygen $\left(\mathrm{PaO}_{2} / \mathrm{FIO}_{2}\right)$, airway pressure, cytokines in bronchoalveolar lavage fluid (BALF), and mechanical ventilation time in the ICU. The aim of this prospective, randomized, double-blinded trial was to investigate the protective effect of budesonide against pulmonary injury after $\mathrm{CPB}$. The primary outcome of this study was the lowest $\mathrm{PaO}_{2} / \mathrm{FIO}_{2}$ after $\mathrm{CPB}$. The secondary outcomes of the study were the recovery of patients' pulmonary function and systemic and local inflammation.

\section{MATERIALS AND METHODS}

To investigate the effectiveness of budesonide for preventing lung injury induced by $\mathrm{CPB}$, this prospective, single-center, randomized, parallel-group, double-blinded trial (Chinese Clinical Trial Registry: ChiCTR-IPC-15006179, 3/31/2015, http://www.chictr.org.cn/edit.aspx? $\mathrm{pid}=10693 \& \mathrm{htm}=4$ ) was approved by the Ethics Committee of Harbin Medical University (IRB: HMUIRB20140011) and performed at the Second Affiliated Hospital of Harbin Medical University. Our study was conducted according to the ethical standards stated in the 1964 Declaration of Helsinki and its later amendments. Informed written consent was obtained from all patients. All the participants who had a European System for Cardiac Operative Risk Evaluation II score less than 6 (medium risk) were recruited into the study by referral. In this study, all of the patients had a long preoperative hospital stay because of the need for improved cardiac function. Once their cardiac function had improved sufficiently for operation (cardiac function II class), the patients were enrolled. The primary outcome of the original protocol was changed to the lowest oxygen index.

Adult inpatients, aged 25 to 65 years, who had a European System for Cardiac Operative Risk Evaluation II score less than 6 and were scheduled for elective cardiac surgery, including valvular replacement surgery (mitral valve, tricuspid, or aortic valve replacement surgery), left atrial myxoma resection, right ventricular outflow tract reconstruction, closure of patent ductus arteriosus, repair of endocardial cushion defect, or congenital heart surgery (atrial or ventricular septal defect repair) involving CPB, between May 2015 and December 2015, were considered for enrollment in this study. We screened a total of 100 patients, and 7 patients who decided to receive further treatment in another hospital were excluded from consideration. From the remaining 93 patients, those who met the following criteria were excluded: smoker or smoking cessation within less than 2 weeks, body mass index greater than $35 \mathrm{~kg} / \mathrm{m}^{2}$, pulmonary hypertension or lung dysfunction (vital capacity or forced expiratory volume at 1 second $<50 \%$ of predicted values), or use of systemic or inhaled glucocorticoids within 2 weeks. Patients with autoimmune diseases, infection (leukocytes $<4.0 \times 10^{9}$ or $>10 \times 10^{9} / \mathrm{L}$ ), pleural effusion, lung infection, hypoproteinemia (total protein $<60 \mathrm{~g} / \mathrm{L}$ or albumin $<40 \mathrm{~g} / \mathrm{L}$ ), chronic obstructive pulmonary disease, or asthma also were excluded. Patients with any other major organ failure were excluded. Patients requiring repeat valve replacements also were excluded.

After the exclusion of 33 patients according to the above criteria as outlined in Figure 1, the remaining 60 patients were allocated by sequentially blocked randomization into 2 groups: the saline group $(\mathrm{n}=30)$ and the budesonide group $(\mathrm{n}=30)$ using a random number table. In this study, 6 blocks were set, and each block contained 10 patients. Ten nonrepeated numbers were selected from the random number table. These 10 numbers were allocated to the 10 recruited patients according to the order. The first 5 patients who were assigned the first 5 numbers were allocated to the saline group, and the other 5 patients were allocated to the budesonide group. This process was repeated 6 times for random allocation of all 60 patients into the 2 groups with a 1:1 ratio. The randomization and allocation were blinded to the investigators and patients, except for the one anesthesiologist, who enrolled the patients, generated randomization, and prepared drugs. The patients in the saline and budesonide groups were nebulized, respectively, with $4 \mathrm{~mL}$ saline or $2 \mathrm{mg}$ budesonide (in $4 \mathrm{~mL}$ ) at 24, 12, and 0.5 hours before induction of anesthesia. Performance of BALF twice would result in approximately $40 \mathrm{~mL}$ saline remaining in the lung, and the residual saline would influence the gas exchange function after surgery, especially in aged patients. To avoid the influence of residual saline on lung gas exchange function, we enrolled patients aged 25 to 65 years without preoperative lung dysfunction.

Three anesthesiologists performed the study. The first anesthesiologist had access to the randomization codes and prepared the saline or budesonide samples for nebulization. This anesthesiologist was not involved with the care of any enrolled patients or assessment of the end points. The second anesthesiologist performed the anesthesia, and the third anesthesiologist collected the samples and analyzed the data. All preoperative cardiac medications were continued until the morning of surgery. All patients were given an intravenous injection of $0.05 \mathrm{mg} \cdot \mathrm{kg}^{-1}$ midazolam, and the radial artery was cannulated under local anesthesia Full anesthesia induced with $1 \mathrm{mg} \cdot \mathrm{kg}^{-1}$ lidocaine, $10 \mu \mathrm{g} \cdot \mathrm{kg}^{-1}$ fentanyl, $0.1 \mathrm{mg} \cdot \mathrm{kg}^{-1}$ pipecuronium, and $0.2 \mathrm{mg} \cdot \mathrm{kg}^{-1}$ etomidate. To collect the BALF and maintain ventilation, after induction, the patients were intubated with a left double-lumen endobronchial tube (size 35 in women and 37 in men; Broncho-Cath, Mallinckrodt Medical, Athlone, Ireland), and its position was confirmed with a fiber-optic bronchoscope (PENTAX, Tokyo, Japan). After intubation, the right internal jugular vein was cannulated. All patients were ventilated with volume-controlled ventilation (tidal volume, $8 \mathrm{~mL} / \mathrm{kg}$; postexpiratory end pressure, $5 \mathrm{cmH}_{2} \mathrm{O} ; \mathrm{FiO}_{2}, 80 \% \pm 5 \%$; inspiratory/expiratory ratio, 1:2; and partial arterial carbon dioxide tension 


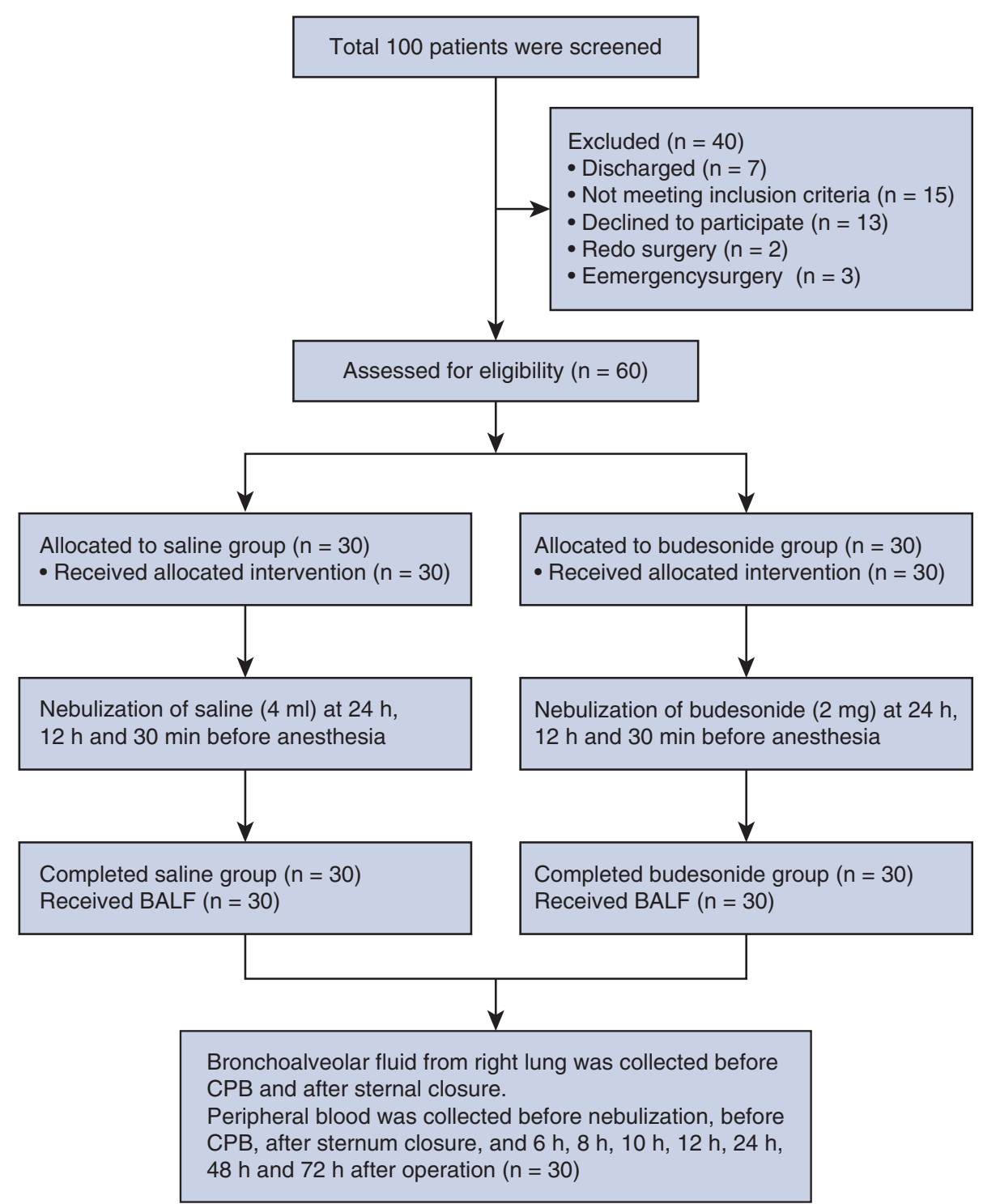

FIGURE 1. Flow diagram of patient enrollment. $B A L F$, Bronchoalveolar lavage fluid; $C P B$, cardiopulmonary bypass.

[Paco 2$], 35-40 \mathrm{~mm} \mathrm{Hg})$. The anesthesia was maintained with fentanyl $\left(10 \mu \mathrm{g} \cdot \mathrm{kg}^{-1} \cdot \mathrm{h}^{-1}\right)$ and sevoflurane $(1.5 \%)$ before the CPB. During the $\mathrm{CPB}$, the anesthesia was maintained with fentanyl $\left(10 \mu \mathrm{g} \cdot \mathrm{kg}^{-1} \cdot \mathrm{h}^{-1}\right)$ and propofol $\left(6 \mathrm{mg} \cdot \mathrm{kg}^{-1} \cdot \mathrm{h}^{-1}\right)$, and the administration of fentanyl and sevoflurane was reintroduced after CPB.

Standardized $\alpha$-stat CPB management was provided to all patients (Videos 1-4). During the $\mathrm{CPB}$, the $\mathrm{pH}$ and $\mathrm{PaCO}_{2}$ were maintained at 7.35 to 7.45 and 35 to $40 \mathrm{~mm} \mathrm{Hg}$, respectively, and body temperature was maintained at $30^{\circ} \mathrm{C}$ to $32^{\circ} \mathrm{C}$. When $\mathrm{PaO}_{2} / \mathrm{FIO}_{2}$ could not be maintained at greater than 150 , the $\mathrm{FIO}_{2}$ was increased, and the patient was excluded from the study. After $\mathrm{CPB}$, manual ventilation was performed to a peak pressure of $40 \mathrm{cmH}_{2} \mathrm{O}$ twice for 15 seconds before restoration of mechanical ventilation. After the operation, the double-lumen endobronchial tube was exchanged with a tracheal tube (inner diameter of $7 \mathrm{~mm}$ for women and inner diameter of $7.5 \mathrm{~mm}$ for men). Then the patients were transferred to the ICU and received standardized management according to institutional guidelines (Video 5). The tidal volume was applied at $8 \mathrm{~mL} \cdot \mathrm{kg}^{-1}$ with a positive end-expiratory pressure of $5 \mathrm{cmH}_{2} \mathrm{O}$. The tidal volume and $\mathrm{FIO}_{2}$

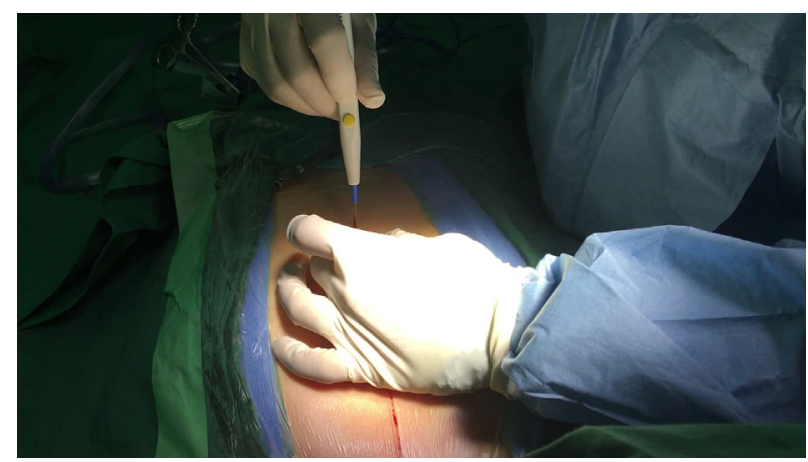

VIDEO 1. Thoracotomy procedure. Video available at: https://www.jtcvs. org/article/S0022-5223(18)32518-2/fulltext. 


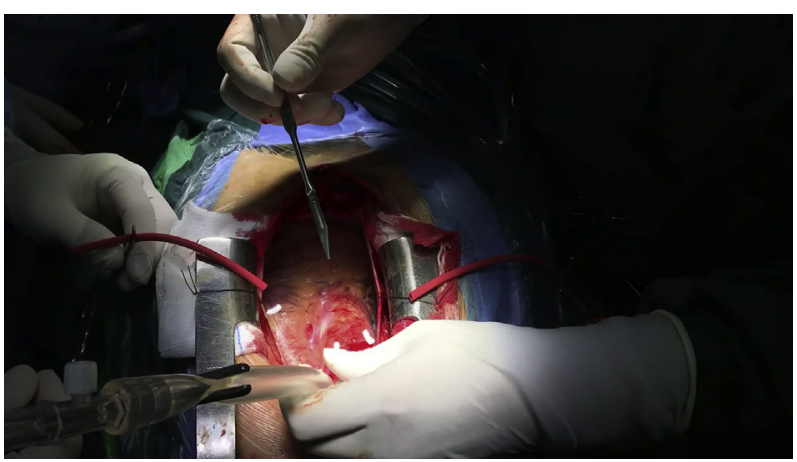

VIDEO 2. Cannulation of the aorta and vena cava. Video available at: https://www.jtcvs.org/article/S0022-5223(18)32518-2/fulltext.

were adjusted to keep the $\mathrm{PaO}_{2} / \mathrm{FIO}_{2}$ ratio greater than 150 and the $\mathrm{PaCO}_{2}$ between 30 and $35 \mathrm{~mm} \mathrm{Hg}$. Weaning from ventilation was started if the patients were hemodynamically stable, the $\mathrm{PaO}_{2} / \mathrm{FIO}_{2}$ ratio was greater than $200,{ }^{17}$ the acid-base balance was normal, chest drainage was less than $80 \mathrm{~mL} \cdot \mathrm{h}^{-1}$, and the body temperature was $36^{\circ} \mathrm{C}$ or greater. All patients underwent an extubation test before extubation. Briefly, when the tidal volume of spontaneous breath recovered to $6 \mathrm{~mL} \cdot \mathrm{kg}^{-1}$ and the respiratory rate was between 12 and 14 breaths per minute, mechanical ventilation was withdrawn for 30 minutes, and during spontaneous breathing under tracheal intubation, the patients were extubated if they were hemodynamically stable and the $\mathrm{PaO}_{2} / \mathrm{FiO}_{2}$ ratio was greater than 200 with air. After weaning from ventilation, the patients were transferred to the ward. If the $\mathrm{PaO}_{2} / \mathrm{FIO}_{2}$ was less than 150 , additional oxygen or a noninvasive ventilator (continuous positive airway pressure) was provided in the ward. Postoperative analgesia was achieved with $0.04 \mu \mathrm{g} /(\mathrm{kg} \cdot \mathrm{h})$ sufentanil. After return to the ward, the patients were encouraged to begin off-bed activity as early as possible if they could maintain cardiopulmonary function without additional drugs.

The $\mathrm{PaO}_{2} / \mathrm{FIO}_{2}$ ratio was determined, and the peripheral blood sample was collected before nebulization, before the $\mathrm{CPB}$, after sternum closure, and $6,8,10,12,24,48$, and 72 hours after the operation. The peak pressure, plateau pressure, and dynamic compliance were monitored with a S/5TM instrument (Datex-Ohmeda Inc, Helsinki, Finland) after intubation, before CPB, after sternal closure, and 2, 4, and 6 hours after admission to the ICU. BALF was collected before CPB and after sternum closure. Briefly, 1 bronchial segment of the right lung lower lobe was selected under a fiber-optic bronchoscope, $40 \mathrm{~mL}$ saline was injected, and the fluid was gently aspirated with a pressure of $-50 \mathrm{cmH}_{2} \mathrm{O}$. The BALF recovery was approximately $50 \%$. The BALF was centrifuged at $1000 \times g$ and $4^{\circ} \mathrm{C}$ for 15 minutes and stored at $-80^{\circ} \mathrm{C}$ for further analysis. The

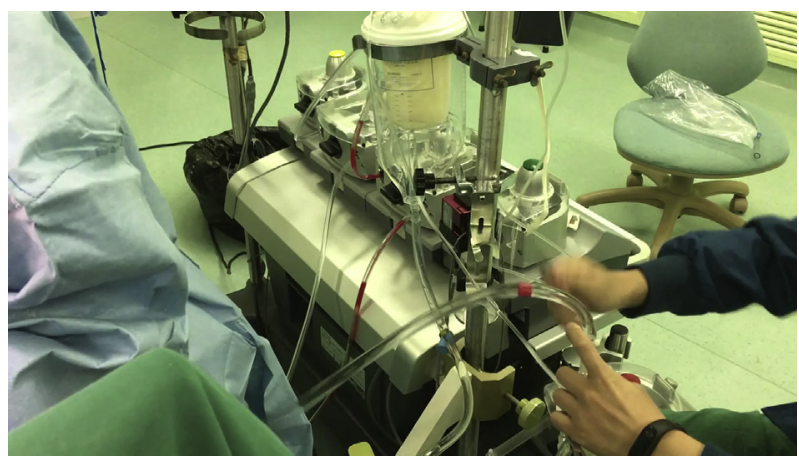

VIDEO 3. CPB procedure. Video available at: https://www.jtcvs.org/ article/S0022-5223(18)32518-2/fulltext.

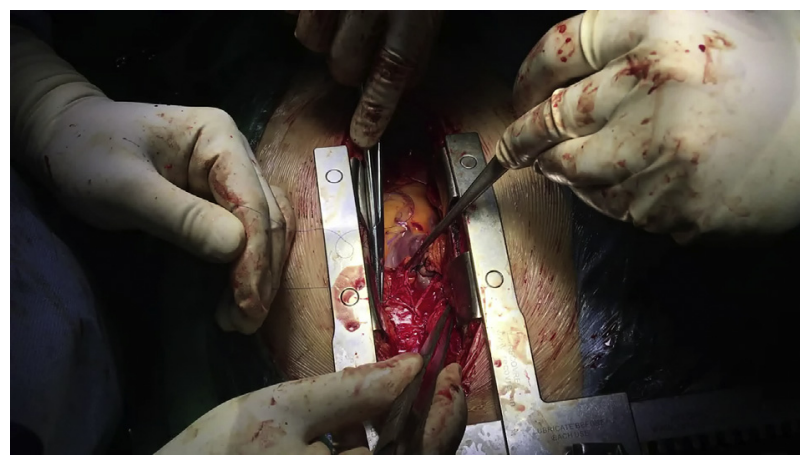

VIDEO 4. Procedure for sternal closure. Video available at: https://www. jtcvs.org/article/S0022-5223(18)32518-2/fulltext.

concentrations of tumor necrosis factor (TNF)- $\alpha$, interleukin (IL)- $1 \beta$, IL-10, complement (C) 3a, C5a, and C-reactive protein (CRP) in the serum and BALF samples were measured. In addition, the neutrophil and macrophage counts and protein and neutrophil elastase concentrations were determined in the BALF. All cytokine concentrations were measured using enzyme-linked immunosorbent assay kits (Wuhan Boster Bio-Engineering, Hubei, China). The ventilation time in the ICU, stay in ICU, time to discharge from the ICU, and length of hospital stay were recorded. The need for noninvasive ventilation (continuous positive airway pressure) in the ward was recorded. Postoperative complications including cardiovascular, pulmonary, cerebral, and urinary adverse events were monitored and recorded. The incidences of postoperative acute respiratory distress syndrome (ARDS) ${ }^{18}$ pulmonary edema, new episodes of atrial fibrillation that could not be converted by amiodarone, myocardial infarction (increase in creatine kinase-MB $\geq 25 \mathrm{ng} / \mathrm{dL}$ and the development of a new pathological $\mathrm{Q}$ wave on the electrocardiogram), acute kidney injury (increase in serum creatinine level by $>50 \%$ or $0.3 \mathrm{mg} / \mathrm{dL}$ from baseline within 48 hours after surgery), and cerebrovascular events were recorded.

To guarantee the safety of patients in both groups, the patient was excluded, and the experiment ended if any severe complication such as lung edema, severe ARDS, heart failure, myocardial infarction, kidney failure, intracranial hemorrhage, or cerebral infarction was detected. Lung complications were monitored with auscultation and imaging examination. In the ICU, all patients received auscultation twice per day, and imaging examination was performed if the auscultation was abnormal. The patient would receive image examination if the auscultation was abnormal. Atelectasis was diagnosed on the basis of evidence from both auscultation and the imaging examination. All postoperative complications were monitored until discharge. The patients were contacted by telephone

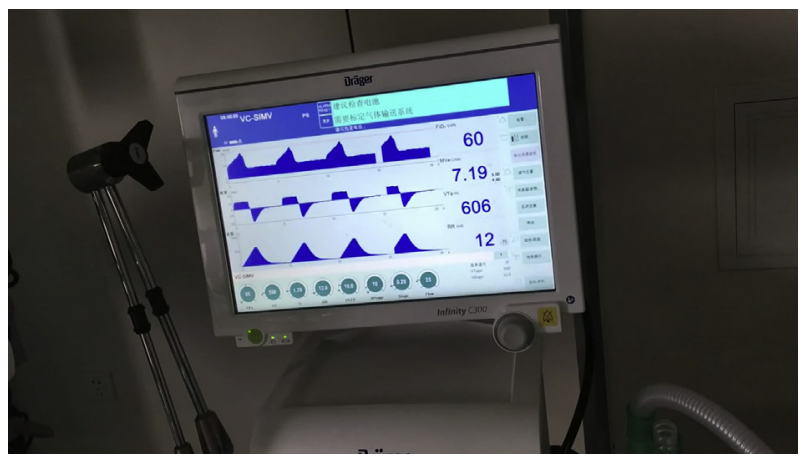

VIDEO 5. Treatment of patients in the ICU. Video available at: https:// www.jtcvs.org/article/S0022-5223(18)32518-2/fulltext. 
at 1, 2, and 6 months after discharge to monitor for respiratory complications, including lung infection, atelectasis, and pneumonia. Cases of lung infection, atelectasis, and pneumonia were examined by community hospitals according to clinical symptoms, biological investigations, and image examinations. All complications were reported to the safety monitoring board.

The $\mathrm{PaO}_{2} / \mathrm{FIO}_{2}$ ratio is a sensitive functional index for lung injury, and we selected the lowest $\mathrm{PaO}_{2} / \mathrm{FIO}_{2}$ postoperative ratio as the primary outcome according to previous study. ${ }^{19}$ The secondary outcomes included the peak pressure, plateau pressure, dynamic compliance, duration of mechanical ventilation, duration of ICU stay, time from end of surgery to discharge (postoperative recovery time), duration of hospital stay, and cytokine concentrations in BALF and serum.

\section{Statistical Analysis}

The normality of data was analyzed with the Shapiro-Wilk test. The normally distributed data are presented as mean \pm standard deviation, and the skewed data are presented as median (range). The primary end point was the lowest mean (standard deviation) value of the $\mathrm{PaO}_{2} / \mathrm{FIO}_{2}$ after operation. According to our clinical experience, the lowest $\mathrm{PaO}_{2} / \mathrm{FIO}_{2}$ after operation occurred between 8 and 10 hours postoperatively in patients with a similar condition to those of this study. Therefore, we used this lowest $\mathrm{PaO}_{2} / \mathrm{FIO}_{2}$ to calculate the sample size. The sample size was based on a pilot study that showed a lowest mean $\mathrm{PaO}_{2} / \mathrm{FiO}_{2}$ of $204 \pm 41$. Twenty-four patients per group were required to detect an a priori outcome difference of 30 with an alpha error of 0.05 and a power of $80 \%$. Therefore, 30 patients per group were studied to compensate for missed cases and deviation from normality.

Categoric data are expressed as number or frequency, and differences in these data were analyzed using the chi-square test or Fisher exact test as appropriate. Intergroup comparisons of demographic data, surgical characteristics, and recovery times were analyzed using $t$ test for normally distributed data and Mann-Whitney test for skewed data. Repeated data over time were analyzed using generalized estimating equation. The normal distributed data were analyzed using unpaired $t$ test analysis. The nondistributed data were analyzed with the nonparametric Wilcoxon rank-sum test (Mann-Whitney $U$ test). To fully evaluate the factors affecting the duration of ventilation in the ICU and stay in the ICU, we used a multiple linear model to analyze the patients' data and surgical-related data. All statistical analyses were performed using SPSS 11.5 for Windows (SPSS, Inc, Chicago, Ill).

\section{RESULTS}

A total of 60 patients completed the study (Figure 1) and were successfully weaned from mechanical ventilation. There were no differences in the patient characteristics, operative data, perioperative fluid balance, and transfusion requirement between the saline and budesonide groups. The preoperative length of hospital stay was counted from the definitive diagnosis to the day of surgery and did not differ significantly between the groups (Table 1). No study patient in either group experienced severe ARDS, pulmonary edema, myocardial infarction, or acute kidney injury. Additionally, no patients developed lung infection, atelectasis, or pneumonia during the first 6 months after CBP. There were 7 and 9 patients in the saline and budesonide groups who had preoperative atrial fibrillation. None of the patients experienced a new episode of atrial fibrillation that could not be converted by amiodarone.
In this study, the lowest $\mathrm{PaO}_{2} / \mathrm{FIO}_{2}$ ratio was at 8 hours postoperatively in the 2 groups. Compared with that in the saline group, the $\mathrm{PaO}_{2} / \mathrm{FIO}_{2}$ ratio was higher in the budesonide group from 8 to 48 hours after surgery (saline vs budesonide: $370 \pm 90$ vs $362 \pm 61,404 \pm 34$ vs $410 \pm 78,370 \pm 53$ vs $380 \pm 80,314 \pm 45$ vs $316 \pm 71$, $209 \pm 42$ vs $242 \pm 68,229 \pm 56$ vs $262 \pm 81,274 \pm 79$ vs $325 \pm 81,243 \pm 46$ vs $295 \pm 54,332 \pm 38$ vs $371 \pm 42,384 \pm 41$ vs $394 \pm 50$ ) (Figure 2). The time to weaning from ventilation and the postoperative recovery time were less in patients who received budesonide, but the time in the ICU and total length of hospital stay did not differ between the groups (Table 2). In the comparison of patient characteristics and surgical data between groups, only "group" as a variable significantly influenced the duration of ventilation in ICU $(P<.05)$. The peak and plateau pressures were lower and compliance was higher in the budesonide group compared with the saline group (Figure 3). Four patients in the saline group required noninvasive ventilation postoperatively in the ward, whereas no patients in the budesonide group required noninvasive ventilation $(P=.12)$.

The concentrations of TNF- $\alpha$, IL- $1 \beta, \mathrm{C} 3 \mathrm{a}, \mathrm{C} 5 \mathrm{a}$, and CRP in the BALF were significantly lower in the budesonide group than in the saline group after sternal closure. In contrast, the level of the anti-inflammatory factor IL-10 after sternum closure was significantly higher in the budesonide group than in the saline group (Figure 4). The numbers of macrophages and neutrophils and the concentrations of protein and neutrophil elastase in the BALF were also lower in the budesonide group compared with the saline group after sternal closure (Figure 5). The serum levels of TNF- $\alpha$, IL-1 $\beta$, C3a, C5a, and CRP were lower and the IL-10 level was higher in the budesonide group than in the saline group (Figure 6).

\section{DISCUSSION}

This study show that inhaled budesonide treatment significantly improved the postoperative $\mathrm{PaO}_{2} / \mathrm{FIO}_{2}$ ratio, shortened the time to weaning from ventilation, increased lung compliance, and reduced systemic and local levels of inflammatory mediators after $\mathrm{CPB}$, all of which promoted postoperative recovery.

Postoperative lung injury induced by CPB prolongs the time to weaning from mechanical ventilation and the length of stay in the ICU. CPB provokes severe systemic inflammation, and alveolar inflammation induced by lung ischemia/reperfusion injury plays a pivotal role in the pathogenesis of $\mathrm{CPB}$-induced lung damage. ${ }^{3}$ Budesonide could increase the $\mathrm{PaO}_{2} / \mathrm{FIO}_{2}$ ratio from 8 to 48 hours after operation and shorten the duration of mechanical ventilation and the postoperative recovery time. These results indicate that preoperative inhaled budesonide 
TABLE 1. Demographic data and surgical characteristics

\begin{tabular}{|c|c|c|c|}
\hline & Saline group $(\mathbf{n}=\mathbf{3 0})$ & Budesonide group $(\mathbf{n}=\mathbf{3 0})$ & $P$ value \\
\hline Age $(y)$ & $52.8 \pm 9.8$ & $52.5 \pm 8.9$ & .45 \\
\hline Gender (male/female) & $11 / 19$ & $12 / 18$ & .79 \\
\hline Height $(\mathrm{cm})$ & $164.7 \pm 5.9$ & $164.4 \pm 6.3$ & .43 \\
\hline Weight $(\mathrm{kg})$ & $66.1 \pm 4.3$ & $65.9 \pm 4.6$ & .42 \\
\hline euroSCORE II score & $4.1 \pm 0.9$ & $4.1 \pm 1.0$ & .50 \\
\hline Cardiac function & $3.4 \pm 0.7$ & $3.3 \pm 0.7$ & .35 \\
\hline Body mass index & $21.5 \pm 1.4$ & $22.0 \pm 1.9$ & .13 \\
\hline Smoking history $\mathrm{n}(\%)$ & $10(33.3)$ & $11(36.7)$ & .79 \\
\hline Congestive heart failure $\mathrm{n}(\%)$ & $4(13.3)$ & $6(20.0)$ & .49 \\
\hline Preoperative LVEF (\%) & $53.1 \pm 4.8$ & $52.9 \pm 4.3$ & .44 \\
\hline \multicolumn{4}{|l|}{ Preoperative medications (n) } \\
\hline Corticosteroids and $\beta 2$-agonists & 0 & 0 & 1 \\
\hline$\beta$-blockers & 6 & 5 & .74 \\
\hline Calcium channel blockers & 7 & 6 & .75 \\
\hline Renin-angiotensin system inhibitors & 4 & 3 & 69 \\
\hline Statin & 3 & 2 & .64 \\
\hline Digoxin & 4 & 6 & .49 \\
\hline Diuretics & 12 & 14 & .61 \\
\hline \multicolumn{4}{|l|}{ Surgical procedure (n) } \\
\hline Aortic valve replacement & 2 & 2 & 1 \\
\hline Mitral valve replacement & 11 & 12 & .79 \\
\hline Aortic/mitral valve replacement & 2 & 3 & .64 \\
\hline Left atrial myxoma resection & 4 & 3 & .69 \\
\hline Right ventricular outflow tract reconstruction & 2 & 1 & .55 \\
\hline Closure of patent ductus arteriosus & 1 & 0 & .31 \\
\hline Repair of endocardial cushion defect & 1 & 2 & .55 \\
\hline Atrial septal defect & 4 & 5 & .72 \\
\hline Ventricular septal defect & 3 & 2 & .64 \\
\hline \multicolumn{4}{|l|}{ Pulmonary function test } \\
\hline FVC; $\%$ predicted & $80.8 \pm 6.1$ & $81.6 \pm 3.6$ & .27 \\
\hline FEV1; \% predicted & $79.4 \pm 4.9$ & $79.6 \pm 5.5$ & .44 \\
\hline FEV1/FVC $(\%)$ & $86.7 \pm 5.6$ & $87.2 \pm 4.9$ & .36 \\
\hline Anesthesia time (min) & $232.6 \pm 40.2$ & $230.5 \pm 40.0$ & .42 \\
\hline Operation time (min) & $195.2 \pm 40.5$ & $191.1 \pm 40.0$ & .35 \\
\hline CPB time (min) & $112.8 \pm 36.6$ & $116.2 \pm 44.3$ & .38 \\
\hline Blood lost volume (mL) & $601 \pm 194$ & $595 \pm 185$ & .45 \\
\hline Urine volume $(\mathrm{mL})$ & $793 \pm 134$ & $784 \pm 146$ & .41 \\
\hline Red blood cell infusion $(\mathrm{mL})$ & $1333 \pm 387$ & $1346 \pm 455$ & .45 \\
\hline Plasma infusion $(\mathrm{mL})$ & $983 \pm 235$ & $980 \pm 308$ & .49 \\
\hline Platelets (U) & 4 & 6 & .49 \\
\hline Cryoprecipitate $(\mathrm{mL})$ & 0 & 0 & 1 \\
\hline Preoperative length of hospital stay (d) & $10.7 \pm 5.9$ & $10.2 \pm 5.4$ & .37 \\
\hline
\end{tabular}

The data are presented as means \pm SD or number. euroSCORE, European System for Cardiac Operative Risk Evaluation; $L V E F$, left ventricular ejection fraction; $F V C$, forced vital capacity; $F E V 1$, forced expiratory volume in 1 second; $F E V l / F V C$, forced expiratory volume in 1 second/forced vital capacity; $C P B$, cardiopulmonary bypass.

improved the lung gas exchange function and promoted the postoperative recovery of patients undergoing CPB.

After CPB, severe pulmonary dysfunction and persistent local or systemic inflammation lead not only to hypoxemia and pulmonary interstitial edema but also to increase airway pressure and decrease lung compliance..$^{20-22}$ Previous research indicated that an increase in airway pressure accompanied by a reduction in compliance is independent risk factor for lung injury. ${ }^{23,24}$ An increase in airway pressure will increase the risk of lung injury perioperatively, and low compliance will impair the ventilation function of patients. In this study, the patients who received budesonide inhalation had a lower airway resistance and a greater change in pulmonary compliance 


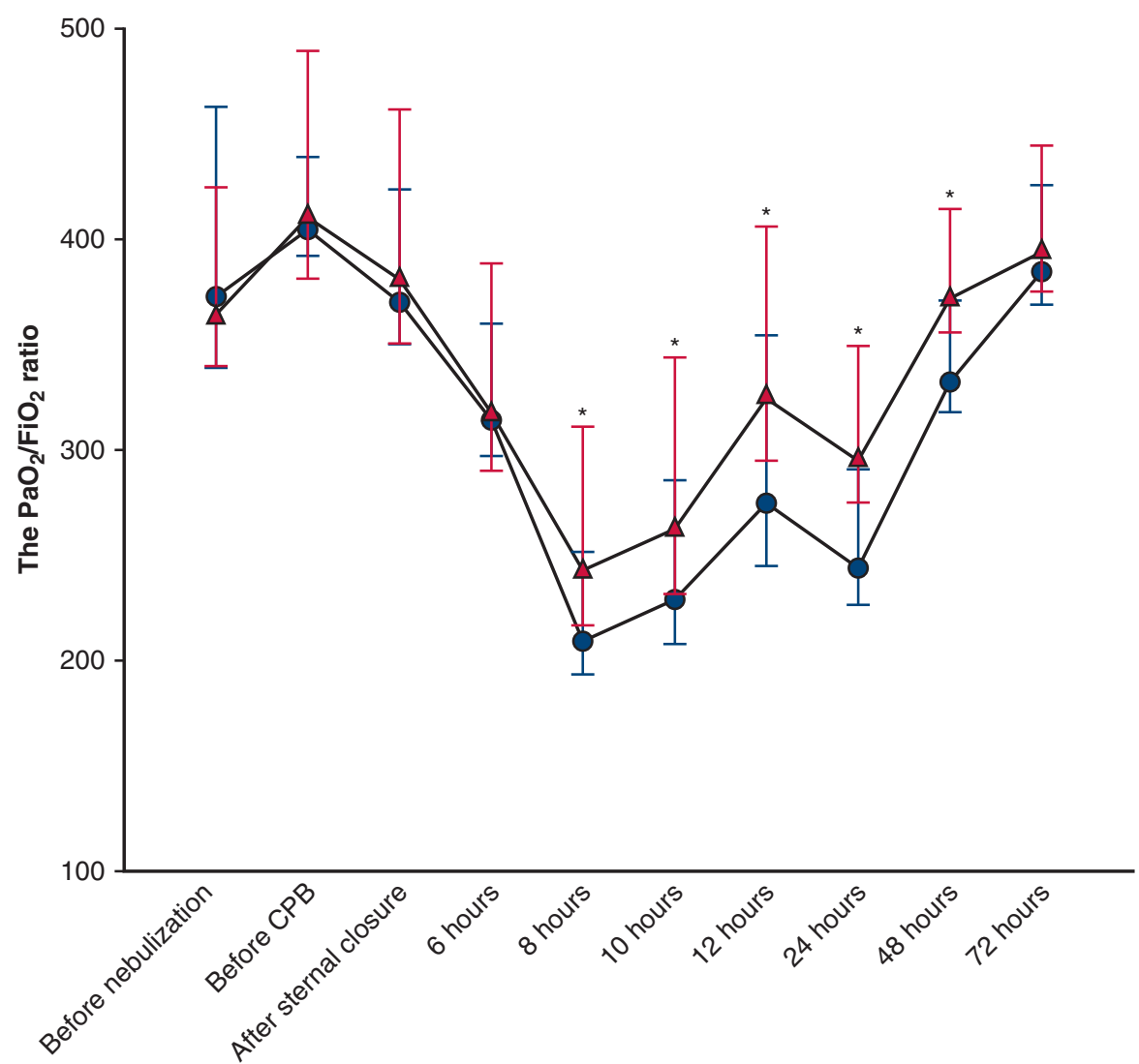

FIGURE 2. Dynamic changes of the $\mathrm{PaO}_{2} / \mathrm{FIO}_{2}$ ratio in the 2 groups $(\mathrm{n}=30)$. Data are expressed as the mean \pm standard deviation $(\mathrm{SD})$ for each group $(\mathrm{n}=30)$. ( $(-)$ and $(\triangle-$ ) represent the saline and budesonide groups, respectively. The positive error $b a r$ represents the SD, and the negative error bar represents the $95 \%$ confidence interval. ${ }^{*} \mathrm{P}<.05$ compared with the saline group. $\mathrm{CPB}$, Cardiopulmonary bypass; $\mathrm{PaO}_{2} / \mathrm{FIO}_{2}$, partial pressure of arterial oxygen to the fraction of inspired oxygen.

from baseline to postoperatively. The exact mechanism by which budesonide improved the pulmonary mechanical status at baseline is unknown. According to the results of an animal study, we speculated that this effect may be attributed to the effect of budesonide on the airway muscles. Animal studies indicated that glucocorticoids can regulate the CD38, cpi-17, and smooth muscle actin levels to improve airway muscle status. ${ }^{25,26}$ More important, our study found budesonide not only improved airway status at baseline but also reduced the airway resistance after CPB. These findings are consistent with those of our previous studies. ${ }^{16,27}$ Moreover, previous research indicated that glucocorticoids can inhibit the contraction of airway smooth muscle, ${ }^{16,28-30}$ and this effect may be due to the regulation of $\mathrm{CD} 38,{ }^{25}$ cpi-17, and $\alpha$-smooth muscle actin in airway smooth muscle by glucocorticoids. ${ }^{26}$

The improvement of pulmonary function with budesonide inhalation may be due to the anti-inflammatory properties of glucocorticoids. ${ }^{9,10,16,31}$ Injury to endothelial cells caused by the inflammatory response ${ }^{2,32}$ or ischemia/reperfusion $^{3}$ will recruit neutrophils and macrophages into the lung and result in damage of epithelial and endothelial cells. ${ }^{7}$ This inflammatory response is characterized by elevated concentrations of TNF- $\alpha$, IL- 1 , and CRP. ${ }^{33}$ We found that budesonide inhalation significantly decreased proinflammatory cytokine and CRP levels in BALF and serum, as well as elastase concentrations and neutrophil and macrophage counts in BALF. The effect of budesonide inhalation on local and systemic inflammation may be associated with inhibition of nuclear factor- $\kappa \mathrm{B}$ activation and monocyte chemoattractant protein-1 expression. $^{34,35}$ Budesonide may also inhibit the recruitment of inflammatory neutrophils and alveolar macrophage infiltration in the lung by reducing the expression of adhesion molecules. ${ }^{36}$ In addition, as an important anti-inflammatory factor, IL-10 can antagonize the effects of TNF- $\alpha$, IL-1, IL-6, and IL- 8 , and inhibit inflammatory cell migration. ${ }^{37}$ This immunoregulated effect of budesonide on the systemic inflammation response syndrome is consistent with the findings of another study. ${ }^{33}$ During CPB, the complement system is also activated. ${ }^{38}$ Activation of the complement system can damage the endothelial integrity and cause accumulation of interstitial 
TABLE 2. Comparison of recovery times between the 2 groups

\begin{tabular}{lccc}
\hline & Saline group $(\mathbf{n}=\mathbf{3 0})$ & Budesonide group $(\mathbf{n}=\mathbf{3 0})$ & $\boldsymbol{P}$ value \\
\hline Time of ventilation in ICU (h) & $20.66(18.25-25.45)$ & $17.41(14.87-19.37)$ & .019 \\
Time of stay in ICU (h) & $22.62(21.39-31.41)$ & $21.37(18.18-23.87)$ & .107 \\
Time from end of surgery to discharge (d) & $13(12-15)$ & $10(9-14)$ & .008 \\
Length of hospital stay (d) & $23(20-31)$ & $19(16-28)$ & .088 \\
\hline
\end{tabular}

The data were presented with median (interquartile range). ICU, Intensive care unit.

fluid. In this study, we found that budesonide inhalation significantly reduced the levels of $\mathrm{C} 3 \mathrm{a}$ and $\mathrm{C} 5 \mathrm{a}$ in the BALF and serum, like other glucocorticoids. ${ }^{34,35}$ Our results showed that budesonide significantly reduced the
CRP levels and further indirectly inhibited C3a and C5a expression after CPB.

Contrary to previous studies, Santos and colleagues ${ }^{39}$ reported that budesonide did not improve the respiratory
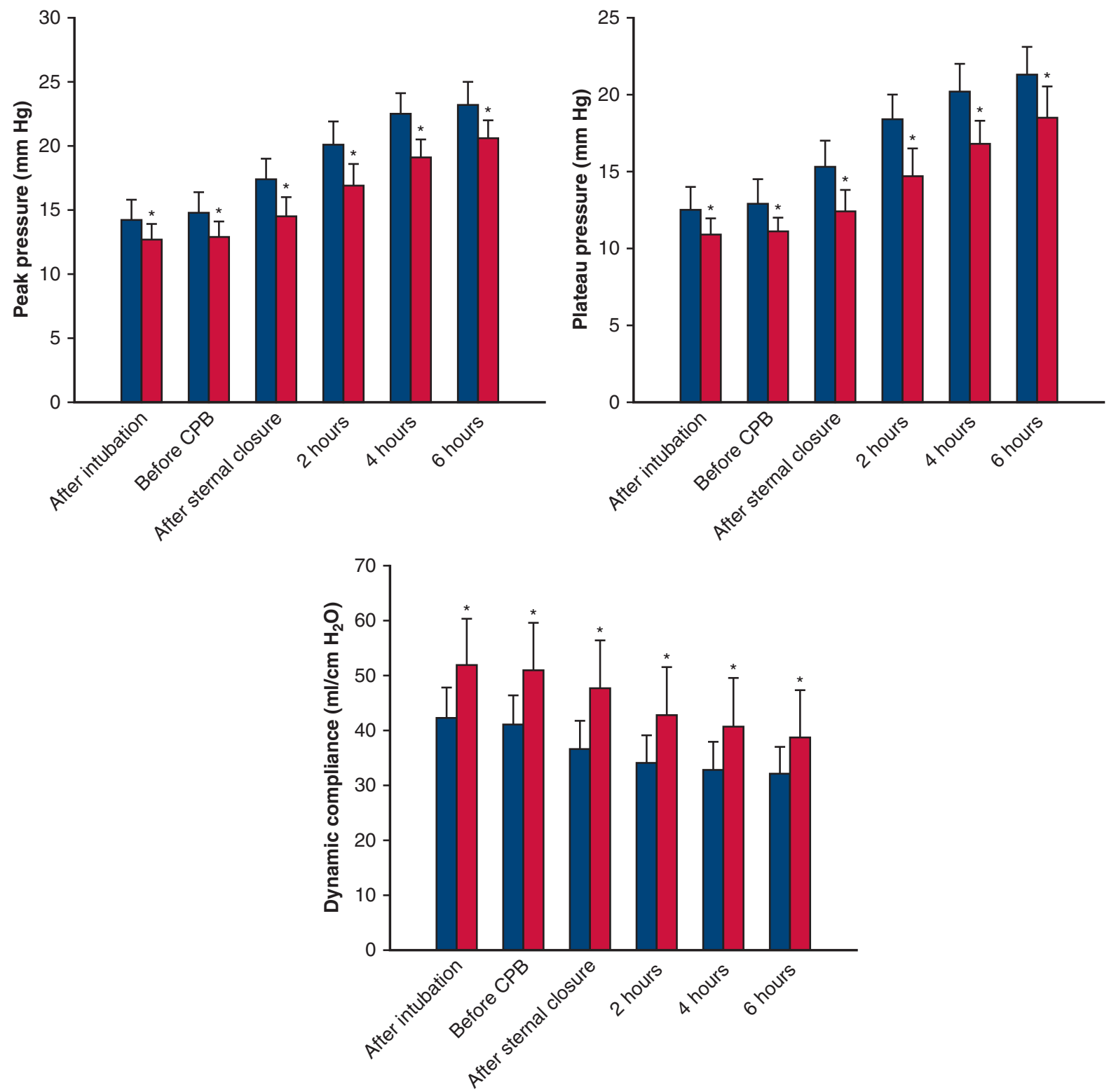

FIGURE 3. Dynamic changes ventilation parameters in the 2 groups. Data are expressed as the mean \pm SD for each group $(n=30)$. and ( represent the saline and budesonide groups, respectively. $* P<.05$ compared with the saline group. $C P B$, Cardiopulmonary bypass. 

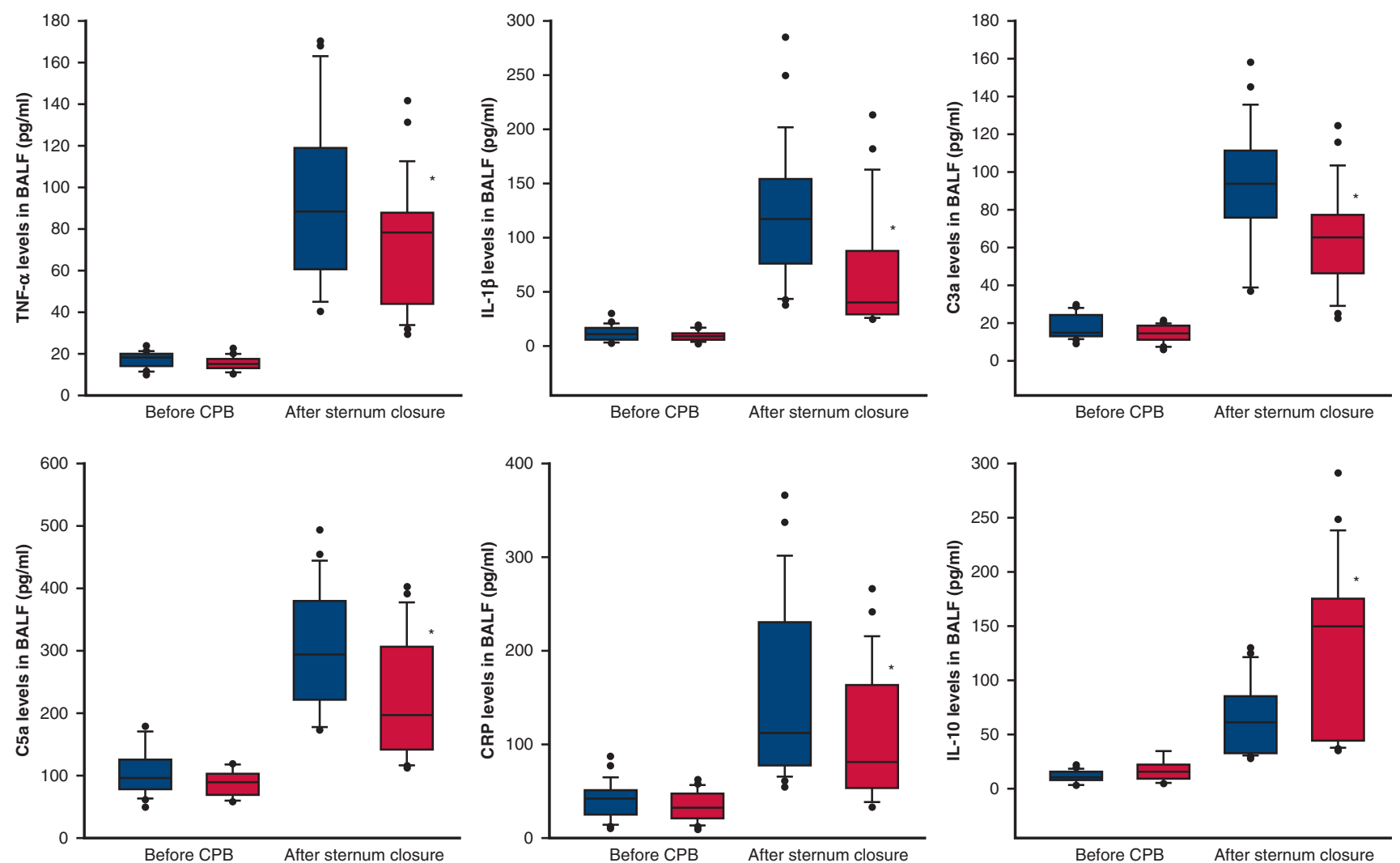

FIGURE 4. The cytokine concentrations in the BALF in the 2 groups $(n=30)$. Levels of TNF- $\alpha$, C3a, C5a, CRP, and IL-10 in the BALF from individual patients. Data are expressed as box-plots of the median, interquartile range, and range for each group $(\mathrm{n}=30)$. The black dots indicate the outliers in each group. ( $\square$ ) and ( $\square$ ) represent the saline and budesonide groups, respectively. $* P<.05$ compared with the saline group. BALF, Bronchoalveolar lavage fluid; $C P B$, cardiopulmonary bypass.

mechanics or reduce IL-6 and IL-8 levels in the BALF of children who underwent CPB. These discrepant results may be due to differences in the timing and method of budesonide inhalation, and the limitations of BALF sample collection and efficiency of budesonide. Santos and colleagues administered budesonide via the breathing circuit, whereas we nebulized the drug preoperatively. In addition, Santos and colleagues collected $1 \mathrm{~mL}$ BALF via a catheter from children aged 3 to 6 months, which could influence the recovery of the BALF. ${ }^{39}$

The budesonide dose was based on reports that a total of $6 \mathrm{mg}$ budesonide had the same effects on systemic inflammation $^{40}$ as systemic administration of $40 \mathrm{mg}$ methylprednisolone. Moreover, research has indicated that $2 \mathrm{mg}$ nebulized budesonide given at 12-hour intervals can effectively treat severe asthma. ${ }^{41}$ Therefore, in this study, we administered $2 \mathrm{mg}$ of nebulized budesonide 3 times at 12-hour intervals for a total dosage of $6 \mathrm{mg}$ budesonide to observe the effect of budesonide on lung injury after CPB. In traditional theory, inhalation of budesonide was believed to provide an anti-inflammatory effect, but rarely a systemic effect, and to decrease the risk of adverse drug reactions compared with intravenous injection because of a favorable ratio of local bioavailability to total systemic bioavailability. ${ }^{42}$ However, in the present study, inhaled budesonide not only reduced proinflammatory factors but also decreased cytokine concentrations in serum. These results may indicate a systemic anti-inflammatory effect of budesonide or be due to blockage of cytokine release from the lung to peripheral blood. This phenomenon requires further investigation. Compared with systemic administration of glucocorticoids, our data suggest that inhaled budesonide provided a local anti-inflammatory effect with less risk of adverse complications, consistent with a previous evaluation of the safety of long-term budesonide. $^{42}$

In this study, the preoperative stay, ventilation time, and total length of the hospital stay were longer than other studies. Although the European System for Cardiac Operative Risk Evaluation was less 6, most of the patients in this study had poor cardiac function (III-IV) and poor pulmonary function secondary to cardiac dysfunction. Therefore, these patients needed a long time to complete the preoperative examination and receive preoperative treatment. Preoperative medicines included a cardiotonic, diuretics, drugs to improve coronary artery function, 

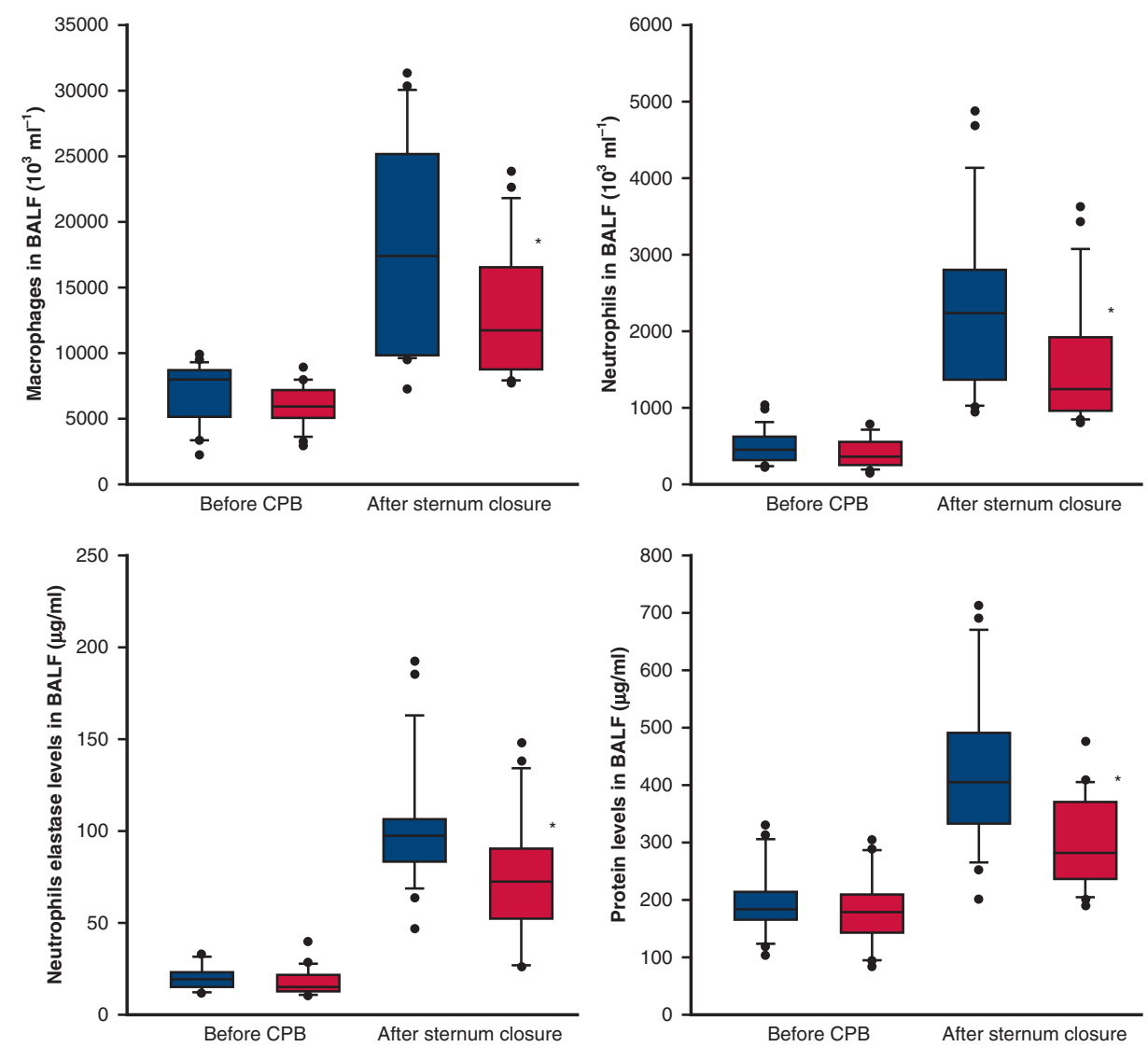

FIGURE 5. The cell infiltration and protein contents in the BALF in the 2 groups. Numbers of macrophages and neutrophils, and the concentrations of total protein and elastase in the BALF. Data are expressed as box-plots of the median, interquartile range, and range for each group ( $\mathrm{n}=30)$. The black dots indicate the outliers in each group. ( $\square$ ) and $(\square$ ) represent the saline and budesonide groups, respectively. $* P<.05$ compared with the saline group $(\mathrm{n}=30) . B A L F$, Bronchoalveolar lavage fluid; $C P B$, cardiopulmonary bypass.

antiarrhythmic drugs, anti-inflammatory drugs, and drugs to improve cardiac and pulmonary function. Second, during the operation, all of the patients underwent BALF twice, and approximately $40 \mathrm{~mL}$ saline remained in the right lung. The residual saline may prolong the ventilation time. Moreover, the ventilation time can be attributed to not only the lung function but also the cardiac function. If the cardiac and pulmonary functions are stable when the patients resumed spontaneous breathing, extubation was performed. Third, because of poor cardiopulmonary function preoperatively, the patients needed at least 1 week of support for cardiopulmonary function. These reasons contributed to the prolonged length of total hospital stay.

In this study, we found that preoperative inhalation of budesonide significantly improved lung gas exchange function, shortened the duration of ventilation in the ICU, and promoted the recovery of patients after CPB. This conclusion is in contrast to the findings of a previous study investigating the effect of intravenous glucocorticoids on lung injury after $\mathrm{CPB} .{ }^{43,44}$ The discrepancy may be due to differences in the pathways by which different glucocorticoids act. It is widely known that systemic corticosteroid administration can lead to immunosuppression and hyperglycemia, and these side effects can negatively influence the outcomes of patients after CPB. Unlike systemic glucocorticoids, inhaled budesonide directly combined with receptor in airway and has been found to reduce acute lung injury in experimental studies, ${ }^{13-15}$ as well as to improve ventilatory mechanics and reduce the inflammatory response to 1-lung ventilation in clinical research. ${ }^{16}$

In our previous study, we found that preoperative nebulization of budesonide can mitigate lung injury after single lung ventilation. ${ }^{16}$ Considering that the severity of lung injury after $\mathrm{CPB}$ is worse than that after single lung ventilation, in the present study, the patients received nebulization 3 times preoperatively. Compared with the repeated administration of nebulization many times in patients with asthma, nebulization 3 times preoperatively was easily accepted by the patients. Moreover, considering that budesonide and the nebulizer are easily obtained, this is a practical approach that could be widely generalized. 

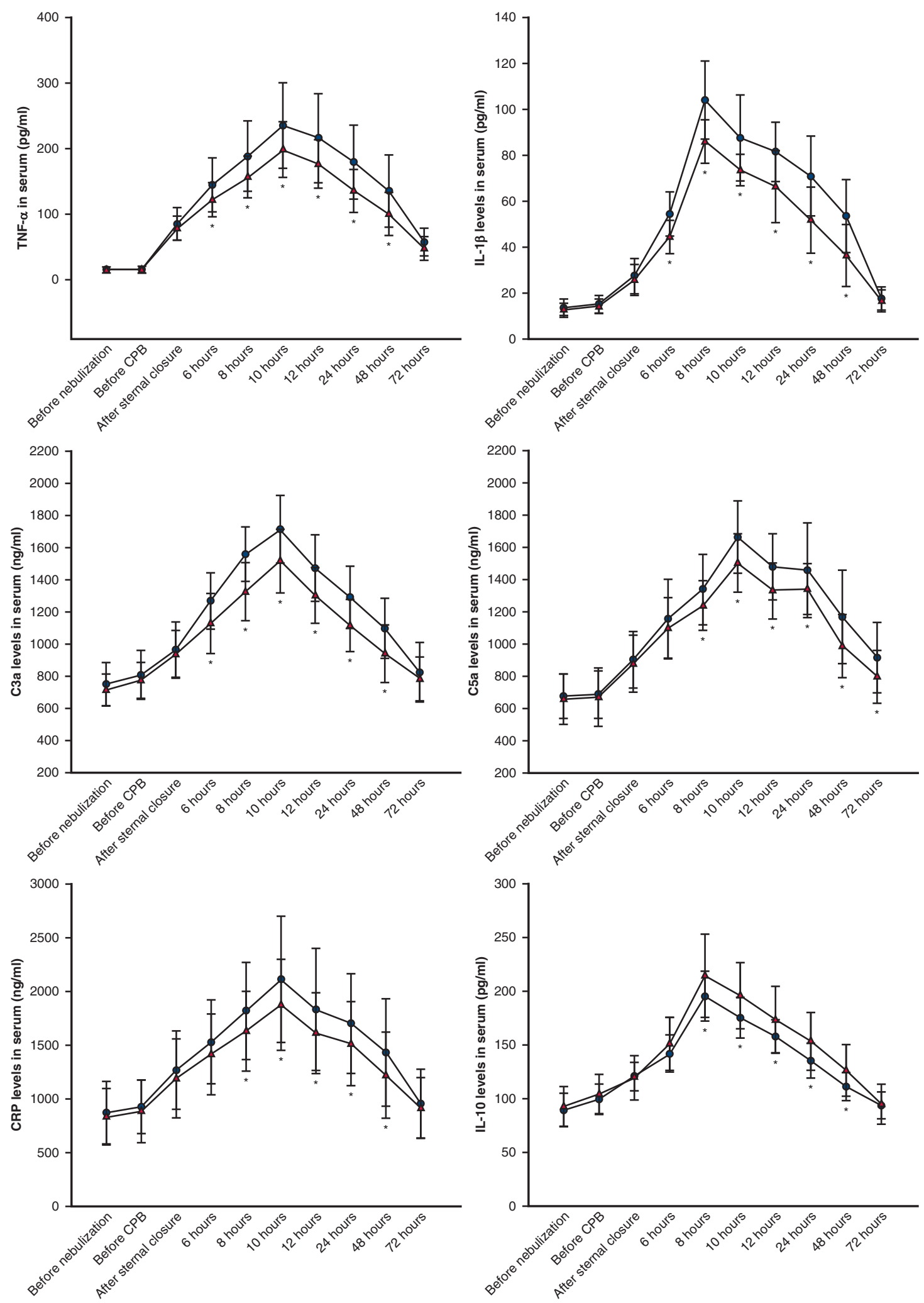

FIGURE 6. Serum cytokine concentrations in the 2 groups $(n=30)$. Serum concentrations of TNF- $\alpha, C 3 a, C 5 a, C R P$, and IL-10 in individual patients were determined. Data are expressed as the mean \pm SD for each group $(\mathrm{n}=30) .(-\mathbf{C})$ and $(\square-$ ) represent the saline and budesonide groups, respectively. $* P<.05$ compared with the saline group. $T N F$, Tumor necrosis factor; $C P B$, cardiopulmonary bypass; $I L$, interleukin; $C R P$, C-reactive protein. 


\section{Study Limitations}

In this study, there were some limitations. First, we did not test lung inflammation after surgery because of the patients' unwillingness. The effect of inhaled budesonide on lung local inflammation and the other possible inducible reactants may not be fully expressed at the time of BALF collection. Second, although preoperative inhaled budesonide shortened the time of ventilation in the ICU and the postoperative recovery time, the difference may have little clinical meaning. The conclusions were obtained from a small sample of patients undergoing first-time, elective cardiac surgery who were randomized to a treatment or placebo group after approximately 1 week of in-hospital treatment. Therefore, larger, more generalizable, multicenter studies are needed to investigate whether prophylactic nebulization of budesonide may benefit patients with a preinjured lung or lung dysfunction. The residual saline of BALF can harm the lung function of patients, and preoperative budesonide treatment may provide more benefits for patients with a preinjured lung or pulmonary dysfunction. In our future research, we will apply this treatment for those patients with pulmonary dysfunction without BALF. Moreover, the length of hospital stay in this study, especially for preoperative treatment, was longer than in previous studies, and this may influence the observed effects of budesonide on length of hospital stay. Such a long period from the preoperative examination and treatment to postoperative discharge may limit the generalizability of the conclusion of this study.

\section{CONCLUSIONS}

The results of this study suggested that preoperative budesonide inhalation can improve respiratory mechanics, decrease proinflammatory cytokine and complement levels, shorten the ventilation time in the ICU, and shorten the postoperative discharge time. The results of this study suggest the beneficial effects of this prophylactic treatment for patients undergoing $\mathrm{CPB}$.

\section{Conflict of Interest Statement}

Authors have nothing to disclose with regard to commercial support.

The authors thank Ziyong Yue, MD, Hongjie Xi, MD, and Yingjie Geng, MD, from the Department of Anesthesia of the Second Affiliated Hospital of Harbin Medical University, Harbin, Heilongjiang Province, China, for assistance in this study.

\section{References}

1. Apostolakis E, Filos KS, Koletsis E, Dougenis D. Lung dysfunction following cardiopulmonary bypass. J Card Surg. 2010;25:47-55.

2. Imura H, Caputo M, Lim K, Ochi M, Suleiman MS, Shimizu K, et al. Pulmonary injury after cardiopulmonary bypass: beneficial effects of lowfrequency mechanical ventilation. J Thorac Cardiovasc Surg. 2009;137: $1530-7$.
3. Slottosch I, Liakopoulos O, Kuhn E, Deppe A, Lopez-Pastorini A, Schwarz D, et al. Controlled lung reperfusion to reduce pulmonary ischaemia/reperfusion injury after cardiopulmonary bypass in a porcine model. Interact Cardiovasc Thorac Surg. 2014;19:962-70.

4. Hirao S, Minakata K, Masumoto H, Yamazaki K, Ikeda T, Minatoya K, et al. Recombinant human soluble thrombomodulin prevents acute lung injury in a rat cardiopulmonary bypass model. J Thorac Cardiovasc Surg. 2017;154: 1973-19783 e1.

5. Rady MY, Ryan T, Starr NJ. Early onset of acute pulmonary dysfunction after cardiovascular surgery: risk factors and clinical outcome. Crit Care Med. 1997;25:1831-9.

6. Qu X, Li Q, Wang X, Yang X, Wang D. N-acetylcysteine attenuates cardiopulmonary bypass-induced lung injury in dogs. J Cardiothorac Surg. 2013;8:107.

7. Yamazaki S, Inamori S, Nakatani T, Suga M. Activated protein C attenuates cardiopulmonary bypass-induced acute lung injury through the regulation of neutrophil activation. J Thorac Cardiovasc Surg. 2011;141:1246-52.

8. Apostolakis EE, Koletsis EN, Baikoussis NG, Siminelakis SN, Papadopoulos GS Strategies to prevent intraoperative lung injury during cardiopulmonary bypass. J Cardiothorac Surg. 2010;5:1.

9. El Azab SR, Rosseel PM, de Lange JJ, Groeneveld AB, van Strik R, van Wijk EM, et al. Dexamethasone decreases the pro- to anti-inflammatory cytokine ratio during cardiac surgery. Br J Anaesth. 2002;88:496-501.

10. von Spiegel T, Giannaris S, Wietasch GJ, Schroeder S, Buhre W, Schorn B, et al Effects of dexamethasone on intravascular and extravascular fluid balance in patients undergoing coronary bypass surgery with cardiopulmonary bypass. Anesthesiology. 2002;96:827-34.

11. Dieleman JM, Nierich AP, Rosseel PM, van der Maaten JM, Hofland J, Diephuis JC, et al, Dexamethasone for Cardiac Surgery Study Group. Intraoperative high-dose dexamethasone for cardiac surgery: a randomized controlled trial. JAMA. 2012;308:1761-7.

12. Whitlock RP, Devereaux PJ, Teoh KH, Lamy A, Vincent J, Pogue J, et al; SIRS Investigators. Methylprednisolone in patients undergoing cardiopulmonary bypass (SIRS): a randomised, double-blind, placebo-controlled trial. Lancet. 2015;386:1243-53.

13. Kohno M, Haramoto M, Nakajima O, Yang L, Hinotsu S, Yokohira M, et al Antedrug budesonide by intrapulmonary treatment attenuates bleomycininduced lung injury in rats with minimal systemic adverse effects. Biol Pharm Bull. 2010;33:1206-11.

14. Smith A, Brown R, Jugg B, Platt J, Mann T, Masey C, et al. The effect of steroid treatment with inhaled budesonide or intravenous methylprednisolone on phosgene-induced acute lung injury in a porcine model. Mil Med. 2009;174 1287-94.

15. Suda K, Tsuruta M, Eom J, Or C, Mui T, Jaw JE, et al. Acute lung injury induces cardiovascular dysfunction: effects of IL-6 and budesonide/formoterol. Am J Respir Cell Mol Biol. 2011;45:510-6.

16. Ju NY, Gao H, Huang W, Niu FF, Lan WX, Li F, et al. Therapeutic effect of inhaled budesonide (Pulmicort(R) Turbuhaler) on the inflammatory response to one-lung ventilation. Anaesthesia. 2014;69:14-23.

17. Shaefi S, Marcantonio ER, Mueller A, Banner-Goodspeed V, Robson SC, Spear K et al. Intraoperative oxygen concentration and neurocognition after cardiac surgery: study protocol for a randomized controlled trial. Trials. 2017;18:600.

18. Force ADT, Ranieri VM, Rubenfeld GD, Thompson BT, Ferguson ND Caldwell E, et al. Acute respiratory distress syndrome: the Berlin Definition. JAMA. 2012;307:2526-33.

19. Kim JC, Shim JK, Lee S, Yoo YC, Yang SY, Kwak YL. Effect of combined remote ischemic preconditioning and postconditioning on pulmonary function in valvular heart surgery. Chest. 2012;142:467-75.

20. Mahmoud AB, Burhani MS, Hannef AA, Jamjoom AA, Al-Githmi IS, Baslaim GM. Effect of modified ultrafiltration on pulmonary function after cardiopulmonary bypass. Chest. 2005;128:3447-53.

21. Huang H, Yao T, Wang W, Zhu D, Zhang W, Chen H, et al. Continuous ultrafiltration attenuates the pulmonary injury that follows open heart surgery with cardiopulmonary bypass. Ann Thorac Surg. 2003;76:136-40.

22. Sacuto Y, Sacuto T. Early pulmonary compliance increase during cardiac surgery predicted post-operative lung dysfunction. Perfusion. 2017;32:631-8.

23. Fernandez-Perez ER, Keegan MT, Brown DR, Hubmayr RD, Gajic O Intraoperative tidal volume as a risk factor for respiratory failure after pneumonectomy. Anesthesiology. 2006;105:14-8.

24. Licker M, de Perrot M, Spiliopoulos A, Robert J, Diaper J, Chevalley C, et al Risk factors for acute lung injury after thoracic surgery for lung cancer. Anesth Analg. 2003;97:1558-65. 
25. Tirumurugaan KG, Kang BN, Panettieri RA, Foster DN, Walseth TF, Kannan MS. Regulation of the cd38 promoter in human airway smooth muscle cells by TNF-alpha and dexamethasone. Respir Res. 2008;9:26.

26. Goldsmith AM, Hershenson MB, Wolbert MP, Bentley JK. Regulation of airway smooth muscle alpha-actin expression by glucocorticoids. Am J Physiol Lung Cell Mol Physiol. 2007;292:L99-106.

27. Gao W, Ju N. Budesonide inhalation ameliorates endotoxin-induced lung injury in rabbits. Exp Biol Med (Maywood). 2015;240:1708-16.

28. Long-term effects of budesonide or nedocromil in children with asthma. The Childhood Asthma Management Program Research Group. $N$ Engl J Med. 2000;343:1054-63.

29. Prosperini G, Rajakulasingam K, Cacciola RR, Spicuzza L, Rorke S, Holgate ST, et al. Changes in sputum counts and airway hyperresponsiveness after budesonide: monitoring anti-inflammatory response on the basis of surrogate markers of airway inflammation. J Allergy Clin Immunol. 2002;110:855-61.

30. Subbarao P, Dorman SC, Rerecich T, Watson RM, Gauvreau GM, O'Byrne PM. Protection by budesonide and fluticasone on allergen-induced airway responses after discontinuation of therapy. J Allergy Clin Immunol. 2005;115:745-50.

31. Silva PL, Garcia CS, Maronas PA, Cagido VR, Negri EM, DamacenoRodrigues NR, et al. Early short-term versus prolonged low-dose methylprednisolone therapy in acute lung injury. Eur Respir J. 2009;33:634-45.

32. Damgaard S, Nielsen $\mathrm{CH}$, Andersen LW, Bendtzen $\mathrm{K}$, Tvede $\mathrm{M}$, Steinbruchel DA. Cell saver for on-pump coronary operations reduces systemic inflammatory markers: a randomized trial. Ann Thorac Surg. 2010;89:1511-7.

33. Morariu AM, Loef BG, Aarts LP, Rietman GW, Rakhorst G, van Oeveren W, et al. Dexamethasone: benefit and prejudice for patients undergoing on-pump coronary artery bypass grafting: a study on myocardial, pulmonary, renal, intestinal, and hepatic injury. Chest. 2005;128:2677-87.

34. Lasa M, Abraham SM, Boucheron C, Saklatvala J, Clark AR. Dexamethasone causes sustained expression of mitogen-activated protein kinase (MAPK) phosphatase 1 and phosphatase-mediated inhibition of MAPK p38. Mol Cell Biol. 2002;22:7802-11.

35. Mittelstadt PR, Ashwell JD. Inhibition of AP-1 by the glucocorticoid-inducible protein GILZ. J Biol Chem. 2001;276:29603-10.
36. Wilson SJ, Wallin A, Della-Cioppa G, Sandstrom T, Holgate ST. Effects of budesonide and formoterol on NF-kappaB, adhesion molecules, and cytokines in asthma. Am J Respir Crit Care Med. 2001;164:1047-52.

37. Opal SM, DePalo VA. Anti-inflammatory cytokines. Chest. 2000;117: 1162-72.

38. Laffey JG, Boylan JF, Cheng DC. The systemic inflammatory response to cardiac surgery: implications for the anesthesiologist. Anesthesiology. 2002;97: 215-52.

39. Santos AR, Heidemann SM, Walters HL III, Delius RE. Effect of inhaled corticosteroid on pulmonary injury and inflammatory mediator production after cardiopulmonary bypass in children. Pediatr Crit Care Med. 2007;8: 465-9.

40. Sun X, He Z, Zhang J, Deng J, Bai J, Li M, et al. Compare the efficacy of inhaled budesonide and systemic methylprednisolone on systemic inflammation of AECOPD. Pulm Pharmacol Ther. 2015;31:111-6.

41. Lin J, Chen P, Liu C, Kang J, Xiao W, Chen Z, et al. Comparison of fluticasone propionate with budesonide administered via nebulizer: a randomized controlled trial in patients with severe persistent asthma. J Thorac Dis. 2017; 9:372-85.

42. Pauwels RA, Pedersen S, Busse WW, Tan WC, Chen YZ, Ohlsson SV, et al; START Investigators Group. Early intervention with budesonide in mild persistent asthma: a randomised, double-blind trial. Lancet. 2003;361:1071-6.

43. Sobieski MA II, Graham JD, Pappas PS, Tatooles AJ, Slaughter MS. Reducing the effects of the systemic inflammatory response to cardiopulmonary bypass: can single dose steroids blunt systemic inflammatory response syndrome? ASAIO J. 2008;54:203-6.

44. Oliver WC Jr, Nuttall GA, Orszulak TA, Bamlet WR, Abel MD, Ereth MH, et al. Hemofiltration but not steroids results in earlier tracheal extubation following cardiopulmonary bypass: a prospective, randomized double-blind trial. Anesthesiology. 2004;101:327-39.

Key Words: cardiopulmonary bypass, inflammation, lung injury, preoperative budesonide inhalation 